\title{
INDICATORS FOR THE PHYSICAL, CHEMICAL AND BIOLOGICAL FILTERING CAPACITY OF PESTICIDES IN PASTURE AND ORCHARD SOILS
}

\author{
K. MÜLLER ${ }^{1}$, M. DEURER ${ }^{2}$, T. ASLAM ${ }^{2}$, F. REMPT ${ }^{3}$, \\ G. NORTHCOTT ${ }^{2}$, B.E. CLOTHIER ${ }^{2}$, A. RAHMAN ${ }^{1}$ and A. GHANI ${ }^{1}$ \\ ${ }^{1}$ AgResearch, Ruakura Research Centre, Private Bag 3123, Hamilton 3240, \\ New Zealand \\ ${ }^{2}$ Plant \& Food Research, Private Bag 11600, Palmerston North 4442, \\ New Zealand \\ ${ }^{3}$ University of Hohenheim, Stuttgart, Germany
}

Corresponding author: kmuller@hortresearch.co.nz

\begin{abstract}
Recently, the loss of soil organic carbon (SOC) has been reported for some pastoral NZ soils. The impact of decreased SOC on soil filtering capacity for pesticides was investigated using 2,4-D. The hypothesis was that in aggregated soils the filtering capacity for organic compounds depends on physical, chemical and biological properties at the aggregate scale, impacting water sorptivity, pesticide sorption and pesticide degradation respectively, and that these are related to the SOC content. Indicators for these properties were identified, namely the water repellency, SOC content, and microbial biomass and basal respiration rates. Two pairs of sites with the same soil type, texture, land-use and climatic conditions, but with significantly different SOC content within each of the pairs were selected. For hydrophobic soils, a SOC loss tended to have a negative impact on chemical and biological properties, but a positive impact on the physical filtering capacity of aggregates for 2,4-D. Keywords: filtering, aggregates, degradation, sorption, sorptivity, transport, 2,4-D, soil quality.
\end{abstract}

\section{INTRODUCTION}

Soil organic carbon (SOC) plays a major role in the ecosystem services of soils as a filter for contaminants. Recently, a widespread loss of SOC has been reported in New Zealand soils (Schipper et al. 2007). The research described in this paper focuses on the potential consequences of SOC loss for the soil's capacity to filter organic pesticides. The hypothesis is that in aggregated soils the filtering capacity depends on physical, chemical and biological properties of the aggregate structure. The aggregate structure in turn, is a function of SOC.

Aggregates represent a physical barrier for the transport of solutes. Once the solutes have been transferred into the aggregates, they are either immobile or travel much slower than outside of the aggregates (Phillip 1968). Therefore, the transfer of solutes into the aggregates is the first step of filtering an agrichemical as it prevents its rapid downward movement. Water and solutes are absorbed into the aggregates by capillary forces. Generally, these forces increase the finer the texture, the higher the SOC contents and the drier the soil. Soil water repellency reduces or abolishes these capillary forces (Bachmann et al. 2003), disabling the soil's physical component of the filtering capacity. The most important component of the chemical filtering process is the sorption of solutes. It mainly takes place inside the soil aggregates, where the residence time of the chemicals is long as a result of slow flow rates. Biological filtering is equivalent to the biological degradation of organics. As the conditions for thriving microbial communities and activity 
are optimised within aggregates due to the availability of water, SOC and nutrients and the physical protection of micro-organisms, the biological degradation also occurs mainly within aggregates (Bollag \& Liu 1990). Aggregates can be considered as hot spots for the fate of solutes. Filtering processes need to be analysed at the aggregate scale.

The existing soil quality framework designed by Karlen et al. (2003) currently offers no indicators that are relevant to the filtering function of soils. Regulators like Regional Councils and land managers need a reliable method to estimate, for example, if the filtering capacity of their soils increases or decreases as a function of their regional or enterprise scale soil carbon management.

The present study had two objectives:

1. To identify a set of indicators to assess the generic capacity of soils to filter organic pesticides.

2. To validate the indicator framework using 2,4-D acid as an example.

This paper compares how the filtering indicators change due to SOC loss at two sites, and then predicts the soils' filtering capacity for 2,4-D, based on the indicators. The predictions are then verified with actual measurements of the soils' physical, chemical and biological filtering capacity for 2,4-D, namely the water sorptivity, and the sorption and degradation of 2,4-D.

\section{Study sites and soil sampling}

\section{MATERIALS AND METHODS}

Two pairs of sites characterised by significantly different SOC contents due to different management practices but under the same soil type with silt loam texture were selected. The first pair of sites was under horticultural production (organic versus integrated apple orchard) in the Hawke's Bay region and the second pair was under long term permanent pasture in the Waikato. The apple trees in the organic orchard received green-waste compost once a year at a rate of 5 to $10 \mathrm{t} / \mathrm{ha}$, and were not irrigated. The tree rows were grassed and regularly mowed as necessary. A $0.5-\mathrm{m}$ wide strip under the trees of the adjacent integrated apple orchard had been kept vegetation free by regular herbicide applications. The apple trees had been drip-irrigated during the vegetative period, and $50 \mathrm{~kg} \mathrm{~N} / \mathrm{ha}$ as calcium ammonium nitrate fertiliser had been applied annually. Both orchards received lime at a rate of $300 \mathrm{~kg} / \mathrm{ha}$ every 4 years. The second pair of sites consisted of 'camp' and 'non-camp' areas on the same paddock of a permanent pasture that was regularly grazed by sheep. Areas with a slope of about $40^{\circ}$ constituted the main grazing area, which was too steep for sheep to rest ('non-camp' sites). The remainder had little $\left(<10^{\circ}\right)$ to no slope and was used by sheep to rest at night ('camp' sites). Such camp-site areas are known to accumulate sheep manure and have increased SOC (Haynes \& Williams 1999).

Six undisturbed soil cores $(0.3 \times 0.2 \times 0.1 \mathrm{~m})$ were collected from both systems in February 2007. Each field-moist soil slab was divided into four parts. Two parts were used to determine the aggregate size distribution and physical, chemical and biological properties of the macro-aggregates $(>0.25 \mathrm{~mm})$, which represented about 81 and $91 \%$ of the orchard and pasture soils, respectively. The remaining soil was used for measuring water sorptivity, 2,4-D sorption and degradation with intact macro-aggregates.

\section{Indicator framework}

The filtering function by an aggregated soil of an organic agrichemical has a physical, a chemical and a biological component. For each component, indicator properties, 'filtering indicators', were identified. Water repellency was selected as the most important indicator for the soils' physical filtering capacity. This was determined by measuring the contact angle of macro-aggregates of four sizes with the MED test, which is restricted to contact angles equal or larger than $90^{\circ}$ (Roy \& McGill 2002). The soils' chemical filtering capacity, the sorption of chemicals can be approximated by a soil matrix to soil solution partitioning coefficient. For most organic agrichemicals this coefficient is proportional to the SOC content of the soil (Wauchope et al. 2002), which was selected as the indicator for the soil's chemical filtering capacity. The SOC content can be used to 
rank the sorption of organic chemicals in different soils. It was determined by the Dumas Method for \%C using a LECO CNS-2000 Analyzer (Laboratory Equipment Corporation Ltd, Castle Hill, NSW, Australia). The microbial biomass and the basal respiration rate were selected as biological indicators and these were measured with standard methods (Höper 2006; Öhlinger et al. 1996). All filtering indicators were measured separately for four aggregate sizes and then the aggregate size distribution was used to derive an effective filtering indicator for each component of the filtering process.

The physical, chemical and biological filtering of 2,4-D in the soils

Water sorptivity of the macro-aggregate fractions of the four soils was measured with a modified set-up of an existing method (Gerke \& Köhne 2002). Sorption of 2,4-D to the four soils was measured in batch equilibrium experiments (OECD 2000) with intact macro-aggregates. The degradation of 2,4-D was determined in incubation experiments at the aggregate scale, using a modified method of Gonod et al. (2003).

\section{Statistical analysis}

The indicator values were analysed with an analysis of variance (GenStat 9.1.0.150). The differences between averages of indicator values were interpreted to be significant if they were larger than their respective least significant differences (LSD) at the 95\% confidence level $(\mathrm{P} \leq 0.05)$.

\section{Indicator property values}

\section{RESULTS AND DISCUSSION}

The macro-aggregates of the orchard soils had contact angles smaller than $90^{\circ}$. These aggregates will, therefore, exert capillary forces and will absorb water. Within the measuring constraints no impact of SOC loss on the contact angle of either of the orchard soils was detected. In contrast, all soil aggregates from the pastoral sites were hydrophobic when dry, with contact angles equal or larger than $90^{\circ}$. The effective contact angle was significantly higher for the camp than the non-camp site pasture (Table 1). Several other studies reported positive correlations between the SOC contents and the degree of soil water repellency (Kawamoto et al. 2007; Täumer et al. 2004). Woche et al. (2005) also found no such positive correlation and concluded that SOC quality rather than quantity governs soil water repellency. It is predicted that the higher the contact angle is above $90^{\circ}$ the lower the water sorptivity will be.

The effective SOC content was significantly higher for the organic than the integrated orchard (Table 1). The effective SOC content for the macro-aggregates was significantly higher for the camp than for the non-camp site pasture (Table 1). The long-term application of compost or animal manure has been shown to increase SOC contents (Celik et al. 2004). It is predicted that the higher the SOC content is, the higher the soils' 2,4-D sorption will be.

The effective microbial biomass and basal respiration rates were significantly higher for the organic than for the integrated orchard. The effective microbial biomass and basal respiration rates were significantly higher for the camp site than for the non-camp site pasture. It was concluded that the SOC loss led to significantly lower microbial activity of the macro-aggregates in the two systems. A correlation of microbial activity and the soil C status was generally expected (Fliessbach et al. 2007). It is predicted that the higher the microbial activity is, the higher the degradation of 2,4-D will be.

\section{Physical, chemical and biological filtering}

SOC loss led to a decrease in water sorptivities in the orchards surveyed but to an increase in water sorptivities in the pastures surveyed (Fig. 1). Under pasture the sorptivity increased with decreasing water repellency, as predicted. Water repellency decreased the sorptivity at the high SOC camp site to a factor of 50 (comparison ethanol - water sorptivity; data not shown). SOC loss led to a decrease or no change of 2,4-D sorption in both systems, as predicted. The sorption of 2,4-D was a function of the SOC content (Fig. 2). All aggregates showed an exponential mineralisation of 2,4-D with an initial lag phase. The occurrence of a lag phase suggests that the degradation was driven by specialised degrading populations. 2,4-D degradation was significantly higher in the 
TABLE 1: Effective physical, chemical and biological indicator property values and the measured physical, chemical and biological filtering of 2,4-D in the orchard and pasture systems.

\begin{tabular}{|c|c|c|c|c|c|c|c|}
\hline & \multicolumn{2}{|c|}{ Physical } & \multicolumn{2}{|c|}{ Chemical } & \multicolumn{2}{|c|}{ Biological } & \multirow[b]{2}{*}{$\begin{array}{c}\text { 2,4-D } \\
\text { half- } \\
\text { life } \\
\text { (days) }\end{array}$} \\
\hline & $\begin{array}{c}\text { Contact } \\
\text { angle } \\
\left({ }^{\circ}\right)\end{array}$ & $\begin{array}{c}\begin{array}{c}\text { Water } \\
\text { sorptivity } \\
\left(\mathrm{mm} / \mathrm{s}^{0.5}\right)\end{array} \\
\end{array}$ & $\begin{array}{c}\text { SOC } \\
(\%)\end{array}$ & $\begin{array}{l}\text { Sorption } \\
\text { coefficient } \\
\text { (litres } / \mathrm{kg} \text { ) }\end{array}$ & $\begin{array}{c}\text { Microbial } \\
\text { biomass } \\
\text { (mg C/kg } \\
\text { soil) }\end{array}$ & $\begin{array}{c}\text { Respiration } \\
\text { rate }(\mu \mathrm{g} \\
\mathrm{CO}_{2} / \mathrm{g} \text { soil } \\
\text { day })\end{array}$ & \\
\hline \multicolumn{8}{|l|}{ Orchards } \\
\hline Integrated & $<90$ & 0.025 & 1.8 & 3.1 & 402 & 30 & 59 \\
\hline Organic & $<90$ & 0.060 & 3.9 & 2.7 & 1298 & 63 & 90 \\
\hline LSD & n.s. & 0.025 & 0.3 & n.s. & 95 & 9 & 21 \\
\hline \multicolumn{8}{|l|}{ Pastures } \\
\hline Non-camp & 95 & 0.010 & 4.8 & 8.8 & 571 & 57 & 88 \\
\hline Camp & 101 & 0.003 & 8.5 & 18.4 & 853 & 80 & 66 \\
\hline LSD & 2 & 0.005 & 0.5 & 3.5 & 91 & 8 & 14 \\
\hline
\end{tabular}

'low-carbon' integrated orchard than the 'high-carbon' organic orchard, which was not as predicted (Table 1). The reason for this is hypothesised that 2,4-D specific degrader populations already existed in the integrated orchard while the organic orchard had not received any herbicides for the last 12 years. The camp and non-camp pasture sites had the same herbicide application history. The 'high-carbon' camp site pasture degraded 2,4-D significantly faster than the 'low-carbon' non-camp site, as predicted (Table 1).

\section{Validation of the indicator framework}

The performance of the filtering indicators for 2,4-D in the two systems at the aggregate scale was validated. The lack of soil water repellency successfully indicated that sorptivities in the orchard soils were not limited. The occurrence of water repellency successfully indicated the extremely small sorptivities of the pastoral soils. The organic carbon content was in principal a useful indicator for 2,4-D sorption to orchard and pasture soils. Basal respiration rate and microbial biomass carbon successfully indicated 2,4-D degradation provided the sites had a similar history of 2,4-D applications.

Overall the data on 2,4-D collected in this work supported the hypothesis that the topsoil's filtering capacity for agrichemicals depends on physical, chemical and biological properties of the aggregate structure. At this stage it is suggested that the filtering indicators should be further tested with other organic agrichemicals. In the future the indicator framework might be used to assess the quality of a soil's filtering function for organic agrichemicals from the local to the landscape scale.

\section{REFERENCES}

Bachmann J, Woche S K, Goebel M-O, Kirkham M B, Horton R 2003. Extended methodology for determining wetting properties of porous media. Water Resources Research 39: 1353 [DOI:10.1029/2003WR002143,2003].

Bollag JM, Liu SY 1990. Biological transformation processes of pesticides. In: Cheng $\mathrm{HH}$ ed. Pesticides in the soil environment: processes, impacts and modelling. SSSA, Masison, WI, USA. Pp. 169-211.

Celik I, Ortas I, Kilic S 2004. Effects of compost, mycorrhiza, manure and fertilizer on some physical properties of a Chromoxerert soil. Soil \& Tillage Research 78: 59-67. 


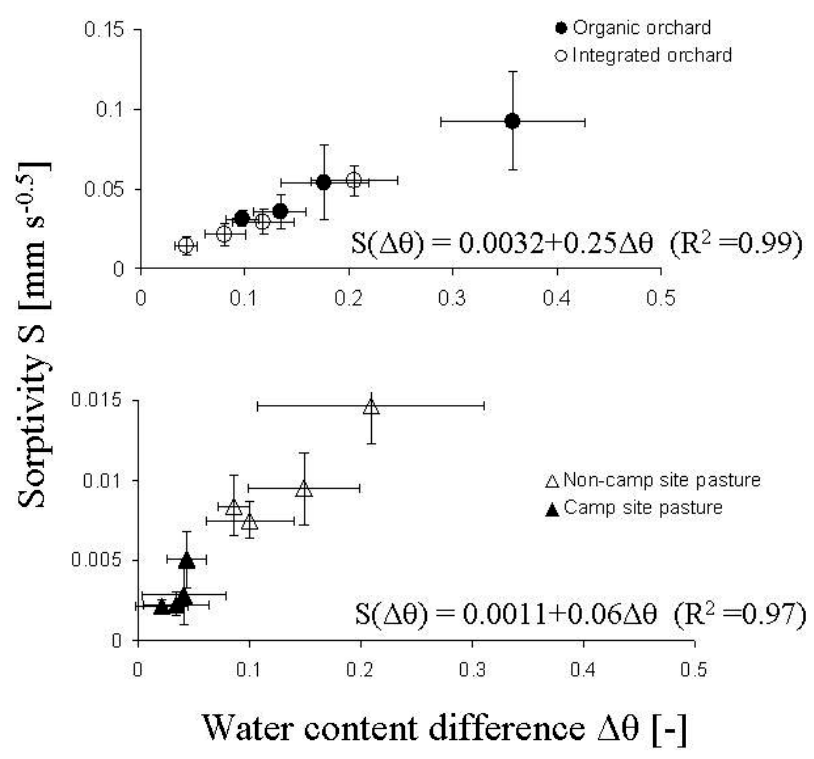

FIGURE 1: Water sorptivity as a function of the water content difference (measured at the beginning and the end of the experiment) measured at four macro-aggregate sizes $(>4.75,2.8-4.75,1.0-2.8,0.25-1.0 \mathrm{~mm})$. Top: Sorptivities in the integrated and the organic orchard. Bottom: Sorptivities in the non-camp and the camp site pasture. The error bars shown indicate one standard deviation.

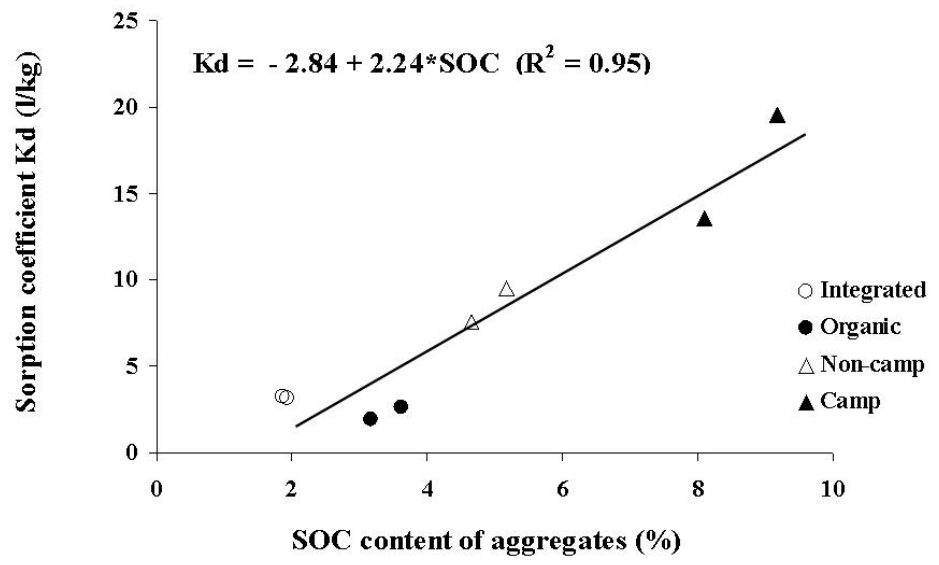

FIGURE 2: 2,4-D sorption coefficients as a function of the SOC contents measured at two macro-aggregate sizes $(>2.8,2.8-0.25 \mathrm{~mm})$ of the orchard and pasture systems. The regression line and equation are indicated on the figure. 
Fliessbach A, Oberholzer HR, Gunst L, Mäder P 2007. Soil organic matter and biological soil quality indicators after 21 years of organic and conventional farming. Agriculture Ecosystems \& Environment 118: 273-284.

Gerke H, Köhne JM 2002. Estimating hydraulic properties of soil aggregate skin from sorptivity and water retention. Soil Science Society of America Journal 66: 26-36.

Gonod LV, Chenu C, Soulas G 2003. Spatial variability of 2,4-dichlorophenoxyacetic acid $(2,4-\mathrm{D})$ mineralisation potential at a millimetre scale in soil. Soil Biology and Biochemistry 35: 373-382.

Haynes RJ, Williams PH 1999. Influence of stock camping behavior on the soil microbiological and biochemical properties of grazed pastoral soils. Biology \& Fertility of Soils 28: 253-258.

Höper H 2006. Substrate-induced respiration. In: Bloem J, Hopkins DW, Benedetti A ed. Microbiological methods for assessing soil quality. CAB International, Wallingford, UK. Pp. 84-92.

Kawamoto K, Moldrup P, Komatsu T, de Jonge LW, Oda M 2007. Water repellency of aggregate size fractions of a volcanic ash soil. Soil Science Society of America Journal 71: 1658-1666.

Karlen DL, Andrews SS, Weinhold BJ, Doran JW 2003. Soil quality: Humankind's foundation for survival. Journal of Soil Water Conservation 58: 171-179.

OECD 2000. Estimation of the adsorption coefficient (Koc) in soil and sewage sludge using high performance liquid chromatography (HPLC). OECD Report 106, Paris, France. 45 p.

Öhlinger R, Beck T, Heilmann B, Beese F 1996. Soil respiration. In: Schinner F, Öhlinger R, Kandeler E, Margesin R ed. Methods in soil biology. Springer-Verlag, Berlin, Germany. Pp. 93-110.

Phillip JR 1968. The theory of absorption in aggregated media. Australian Journal of Soil Research 6: 1-19.

Roy JL, McGill WB 2002. Assessing soil water repellency using the molarity of ethanol droplet (MED) test. Soil Science 167: 83-97.

Schipper LA, Baisden WT, Parfitt RL, Ross C, Claydon JJ, Greg A 2007. Large losses of soil $\mathrm{C}$ and $\mathrm{N}$ from soil profiles under pasture in New Zealand during the past 20 years. Global Change Biology postprint: doi:10.1111/j.1365-2486.2007.01366.x.

Täumer K, Stoffregen H, Wessolek G 2004. Determination of repellency distribution using soil organic matter and water content. Geoderma 125: 107-115.

Wauchope RD, Yeh S, Linders JBHJ, Klaskowski R, Tanaka K, Rubin B, Katayama A, Kördel W, Gerstl Z, Lane M, Unsworth JB 2002. Review. Pesticide soil sorption parameters: theory, measurement, uses, limitations and reliability. Pest Management Science 58: 419-445.

Woche SK, Goebel MO, Kirkham MB, Horton R, Ploeg RR, Bachmann J 2005. Contact angle of soils as affected by depth, texture, and land management. European Journal of Soil Science 56: 239-251. 